\title{
ANALISIS KINERJA MESIN GF FSSZ 65/132 B DENGAN METODE OVERALL EQUIPMENT EFFECTIVENESS (OEE) DI PT PRN
}

\author{
Hermanto \\ Prodi Teknik Industri Fakultas Teknik dan Ilmu Komputer \\ Universitas Indraprasta PGRI Jakarta \\ Email: hers3sm@gmail.com / her.ruslan@yahoo.co.id
}

\begin{abstract}
A b s trak
Mengetahui kinerja mesin Graewe Fangli FSSZ 65 / 132 B melalui perhitungan 3 (tiga) matriks OEE (availability, performance, quality) dan mengidentifikasi jenis-jenis kerugian yang menyebabkan rendahnya elemen $O E E$ yang berdampak terhadap kinerja mesin Graewe Fangli FSSZ 65 / 132 B. Metode penelitian yang digunakan adalah deskritif analisis, yaitu menggambarkan ketersediaan, kinerja dan performa mesin Graewe Fangli FSSZ 65 / 132 B berdasarkan data dan informasi yang sebenarnya dengan cara mengumpulkan, menyusun, mengklasifikasi, dan menganalisis khususnya informasi dan data mengenai nilai $O E E$ adalah 46,95 $\%$ yang terdiri dari ketiga faktor $O E E$, antara lain availability rate $98,08 \%$, performance efficiency $56,17 \%$, quality rate 85,22 \%. Hasil pengukuran nilai masing-masing six big losses 47,69\% (idling and minor stopagges), 33,97\% (reduced speed loss), 14,88 \% (yield/scrap losses), 2,03\% (breakdownn losses), 1,43\% (setup loss), $0 \%$ (rework loss). Dari ketiga elemen OEE yang paling signifikan mempengaruhi rendahnya kinerja mesin Graewe Fangli FSSZ 65 / 132 B adalah performance efficiency 56,17\%. Sedangkan jenis kerugian dari six big losses terbesar terdapat pada idling and minor stopagges (47,69\%).
\end{abstract}

Kata Kunci : Kinerja Mesin Graewe Fangli FSSZ 65 / 132 B, Overall Equipment Effectiveness, Six Big Losses.

\section{PENDAHULUAN}

PT PRALON sebagai salah satu perusahaan manufaktur dengan jam operasi mesin yang cukup tinggi yaitu beroperasi 24 jam tentunya akan sedikit mengalami kendala dalam melakukan perawatan. Hal ini didukung dengan proses produksi yang menggunakan banyak mesin yang terintegrasi satu sama lain mulai dari mesin extruder sampai mesin tip table. Dimana pada masingmasing mesin tersebut terdapat beberapa fungsi dan karakteristik yang berbeda-beda. Setelah melakukan studi pendahuluan diketahui terdapat mesin yang masih kurang optimal sehingga dapat menganggu kinerja dalam proses produksi. Mesin tersebut adalah mesin Graewe Fangli FSSZ 65/132 B.

Untuk melakukan identifikasi terhadap kerugian yang dialami, peneliti melakukan pengukuran nilai overall equitment effectiveness (OEE) yang digunakan sebagai dasar dalam mengukur avaibility, performance efficiency, rate of quality, (six big losses) dan juga sebagai peningkatan kinerja mesin dari sistem manufaktur. Hal ini karena $O E E$ adalah cara terbaik untuk memonitor dan menigkatkan efisiensi dari proses manufacturing.

Ikhsan H, 2016: 9 mengungkapkan bahwa "melalui Overall Equipment Efectiveness $(O E E)$ dapat dilakukan pengukuran kinerja mesin guna meningkatkan kinerja mesin secara individu dengan mengurangi kerugian yang diakbatkan oleh tidak efektifnya penggunaan mesin/peralatan". 


\section{METODE PENELITIAN}

Metode analisis dalam penelitian ini dirancang dengan menggunakan Dasar teori tersebut meliputi teori mengenai kinerja mesin, Total Productve Maintenance (TPM), Overall Equipment Efectiveness (OEE), dan teknik - teknik perbaikan kualitas (Diagram Pareto dan Diagram Sebab Akibat). Dengan mengetahui dari six big loses yaitu breakdown loses, set up \& adjusment, iding \& miror stoppages loses, reduce speed, production loses \& start up loses. Analisis-analisis ini dilakukan pada setiap langkah Overall Equipment Efectiveness (OEE) sesuai dengan polanya.

Metode pengumpulan data menggunakan data kuantitatif yang telah direcord oleh penulis selama 3 bulan terakhir. Data tersebut berasal dari pengumpulan data-data dari mesin graewe fangli FSSZ 65/132 B. Secara grafis prosedur perhitungan Overall Equipment Effectiveness dilakukan dalam beberapa tahap yang disertai dengan penjelasan.

Analisis data akan banyak menggunakan langkah-langkah dari metode Overall Equipment Efectiveness (OEE), dalam penelitian ini dirancang dengan menggunakan Dasar teori tersebut meliputi teori mengenai kinerja mesin, menurut Fauzi, Nur A. 2014 Total Productve Maintenance (TPM), Overall Equipment Efectiveness (OEE), dan teknik - teknik perbaikan kualitas (Diagram Pareto dan Diagram Sebab Akibat).

\section{HASIL DAN PEMBAHASAN}

Untuk menghitung nilai availability digunakan rumus sebagai berikut:

$$
\text { Avaibility }=\frac{\text { operation time }}{\text { loading time }} \times 100 \%
$$

Jadi nilai availability mesin graewe fangli FSSZ 65/132 B untuk bulan februari 2017 sebagai berikut :

Tabel 1 Perhitungan nilai availability Bulan Februari 2017

\begin{tabular}{|c|c|c|c|}
\hline Variabel & Perhitungan & Perhitungan data & hasil (menit) \\
\hline Available time & 8 jam ker x 3 shift x $29 \mathrm{hr}$ & $480 \mathrm{mnt} \times 3 \times 29 \mathrm{hr}$ & 41760 \\
\hline $\begin{array}{c}\text { Planned } \\
\text { downtime }\end{array}$ & 0 jam x 3 shift x $29 \mathrm{hr}$ & 0 menit x $3 \times 29 \mathrm{hr}$ & 0 \\
\hline Loading time & $\begin{array}{c}\text { Available time - planned } \\
\text { downtime }\end{array}$ & $41760 \mathrm{mnt}-0 \mathrm{menit}$ & 41760 \\
\hline Downtime & $\begin{array}{c}\text { Lama trauble mesin }+ \text { set up } \\
\text { mesin }\end{array}$ & $840 \mathrm{mnt}+420 \mathrm{mnt}$ & 1260 \\
\hline Operatime time & Loading time - downtime & $41760 \mathrm{mnt}-1260 \mathrm{mnt}$ & 40500 \\
\hline
\end{tabular}

Sumber : data yang sudah diolah

Avaibility feb 2017 : (40500 / 41760) x $100 \%=96,98 \%$

Avaibility mar $2017:(44280 / 44640) \times 100 \%=99,19 \%$

Avaibility april 2017: (42360 / 43200) x $100 \%=98,06 \%$

\section{Perhitungan performance efficiency $(P E)$}

Untuk menghitung nilai performance efficiency digunakan rumusan sebagai berikut :

$$
\text { Performance efficiency }=\frac{\text { prosecessed amount } x \text { ideal cycle time }}{\text { operation time }} \times 100 \%
$$

cycle time adalah siklus waktu proses yang diharapkan dapat dicapai dalam keadaan optimal atau tidak mengalami hambatan. Waktu siklus mesin graewe fangli FSSZ 65/132 B untuk menghasilkan produk pipa HIC conduit diameter $20 \mathrm{~mm}$ adalah 30 detik/ 2 batang (mesin Graewe Fangli FSSZ 65/132 B adalah mesin type twin yang mengeluarkan 2 batang atau 2 unit pipa sekali produksi). Dalam waktu 24 jam atau 3 shift, mesin tersebut mampu menghasilkan 5.760 batang pipa PVC atau sekitar $(5.760 \times 0,364 \mathrm{~kg} /$ batang $=2.097 \mathrm{kilogram} / \mathrm{hari})$. 
Tabel 2 Perhitungan performance efficiency Bulan februari 2017

\begin{tabular}{|c|c|c|c|}
\hline Variabel & Perhitungan & Perhitungan data & Hasil \\
\hline $\begin{array}{c}\text { Operating time dari } \\
\text { avaibility }\end{array}$ & $\begin{array}{c}\text { Loading time } \text { - downtime } \\
\text { (losses avaibility) }\end{array}$ & $\begin{array}{c}41760 \mathrm{menit}- \\
1260 \mathrm{menit}\end{array}$ & $\begin{array}{c}40500 \\
\text { menit }\end{array}$ \\
\hline $\begin{array}{c}\text { Downtime } \\
\text { performance } \\
\text { losses) }\end{array}$ & $\begin{array}{c}\text { Lama quality check + waiting } \\
+ \text { cleaning }\end{array}$ & $\begin{array}{c}0 \text { menit }+0 \\
\text { menit }+0 \text { menit }\end{array}$ & 0 menit \\
\hline $\begin{array}{c}\text { Operating time from } \\
\text { avabiility }\end{array}$ & $\begin{array}{c}\text { Opering downtime (loses } \\
\text { performance)time from } \\
\text { avaibility }\end{array}$ & $\begin{array}{c}40500 \text { menit }-0 \\
\text { menit }\end{array}$ & $\begin{array}{c}40500 \\
\text { menit }\end{array}$ \\
\hline Process amount & $\begin{array}{c}\text { Jumlah bahan yang diproses } \\
\text { oleh mesin (kg) }\end{array}$ & $44620 \mathrm{~kg}$ & $44620 \mathrm{~kg}$ \\
\hline Ideal cycle time & Waktu siklus ideal & 30 detik & 0,5 menit \\
\hline
\end{tabular}

Februari P.eff $=((44620 \times 0,5) / 40500) \times 100 \%=55,09 \%$

Maret P.eff $=((55085 \times 0,5) / 44280) \times 100 \%=62,08 \%$

April P. eff $=((43400 \times 0,5) / 42360) \times 100 \%=51,23 \%$

Tabel 3 Performance efficiency mesin graewe fangli FSSZ 65/132 B

Bulan februari sampai april 2016

\begin{tabular}{|c|c|c|c|c|}
\hline Bulan & $\begin{array}{c}\text { Processed } \\
\text { amount }\end{array}$ & $\begin{array}{c}\text { Ideal cycle } \\
\text { time }\end{array}$ & $\begin{array}{c}\text { Operating } \\
\text { time }\end{array}$ & $\begin{array}{c}\text { Performance } \\
\text { efficiency }\end{array}$ \\
\hline februari & 44.620 & 0,5 & 40500 & $55,09 \%$ \\
\hline Maret & 55.085 & 0,5 & 44280 & $62,20 \%$ \\
\hline April & 43.400 & 0,5 & 42360 & $51,23 \%$ \\
\hline \multicolumn{5}{|c|}{ rata-rata } \\
\hline
\end{tabular}

\section{Perhitungan rate of quality product}

Untuk menghitung nilai rate of quality product digunakan rumusan sebagai berikut :

rate of quality product $=\frac{\text { processed amount }- \text { defect amount }}{\text { processsed amount }} \times 100 \%$

Tabel 4. Perhitungan rate of quality product Bulan februari 2017

\begin{tabular}{|c|c|c|}
\hline Variabel & Perhitungan & Perhitungan data \\
\hline $\begin{array}{c}\text { Processed } \\
\text { amount }\end{array}$ & $\begin{array}{c}\text { total good product } \\
\text { (kilogram) }\end{array}$ & $44620 \mathrm{~kg}$ \\
\hline Deffect amount & product scrap & $7685 \mathrm{~kg}$ \\
\hline
\end{tabular}

Sumbe: data yang sudah diolah

Quality. rate $=(44.620-7.685) / 44.620 \times 100 \%=82,78 \%$

Quality rate $=(55.085-8.056) / 55.085 \times 100 \%=85,37 \%$

Quality rate $=(43.400-5.417) / 43.400 \times 100 \%=87,52 \%$

\section{Perhitungan overall equipment effectivenes (OEE)}

Perhitungan OEE adalah perkalian nilai-nilai avaibility, performance efficiency dan rate of quality product yang sudah diperoleh. OEE $((\%)=$ availability $(\%) x$ performance rate $(\%) x$ quality rate (\%).Jadi nilai overall equipment effectivenes (OEE) mesin graewe fangli FSSZ 65/132 $B$ untuk bulan Februari sampai dengan bulan april 2016 adalah sebagai berikut :

$$
\text { OEE }=98,08 \% \times 56,17 \% \times 85,22 \%=46,95 \%
$$




\section{Perhitungan OEE six big losses}

a. Downtime losses

1) Breakdown Loss (Equipment Failures)

Breakdown Loss $=(840 / 41760) \times 100 \%=2,01 \%$

Tabel 5 Breakdown loss mesin graewe fangli FSSZ 65/132 B

Bulan februari sampai april 2017

\begin{tabular}{|c|c|c|c|}
\hline Bulan & $\begin{array}{c}\text { Total waktu } \\
\text { breakdown } \\
\text { (menit) }\end{array}$ & Loading time (menit) & $\begin{array}{c}\text { Breakdown } \\
\text { losses (\%) }\end{array}$ \\
\hline februari & 840 & 41760 & $2,01 \%$ \\
\hline maret & 0 & 44640 & $0,00 \%$ \\
\hline april & 600 & 43200 & $1,39 \%$ \\
\hline $\begin{array}{l}\text { Total waktu } \\
\text { brakdown mnt }\end{array}$ & 1440 & \multicolumn{2}{|c}{} \\
\cline { 1 - 3 }
\end{tabular}

\section{2) Setup and Adjustment Loss}

Untuk mengetahui besarnya persentase downtime loss yang diakibatkan oleh waktu set up and adjusment tersebut digunakan rumusan sebagai berikut :

$$
\text { Set up and adjusment loss }=(420 / 41760) \times 100 \%=1,01 \%
$$

Tabel 6 Setup and Adjustment Loss mesin graewe fangli Bulan februari sampai april 2017

\begin{tabular}{|c|c|c|c|}
\hline Bulan & $\begin{array}{c}\text { Setup adustement } \\
\text { loses (menit) }\end{array}$ & Loading time (menit) & $\begin{array}{c}\text { Setup adustement } \\
\text { loses (\%) }\end{array}$ \\
\hline februari & 420 & 41760 & $1,01 \%$ \\
\hline maret & 360 & 44640 & $0,81 \%$ \\
\hline april & 240 & 43200 & $0,56 \%$ \\
\hline $\begin{array}{c}\text { Total waktu setup } \\
\text { adjustement }\end{array}$ & 1020 & & \\
\cline { 1 - 3 } & & &
\end{tabular}

\section{Analisis Perhitungan nilai overall equipment effectiveness (OEE)}

Dari hasil perhitungan avaibility (A) pada mesin graewe fangli FSSZ 65/132 B pada bulan februari sampai bulan april 2017, mempunyai nilai 98,08 \%. Mesin mempunyai nilai avaibility $>95 \%$ dalam 3 bulan, dimana pada bulan pertama nilai A sebesar 96,98\%, pada periode kedua mengalami kenaikan menjadi 99,19\% dan bulan ketiga mengalami penurunan menjadi 98,06\%.

Selanjutnya berdasarkan perhitungan setiap bulan mesin selalu jauh berada dibawah standar yang ditetapkan japan institute and plant maintenance (JIPM) dalam kegiatan produksi, karena mempunyai nilai rata-rata kinerja dibawah 0,65 atau $65 \%$. Mesin mempunyai nilai rata-rata kinerja $<95 \%$ dimana pada bulan februari nilainya sebesar 52,09 $\%$, bulan maret $62,20 \%$ dan bulan april 51,23 \%. Pada bulan april mesin mengalami penurunan nilai performance efficiency $(P E)$ yaitu $51,23 \%$.

Dari hasil perhitungan yang telah dilakukan dapat nilai rate of quality pada mesin graewe fangli FSSZ 65/132 B pada bulan februari sampai april 2017, yaitu $>99 \%$. Mesin mempunyai nilai rate of quality $<99 \%$ selama 3 bulan, dimana pada bulan februari nilainya 
sebesar $82,78 \%$, bulan maret nilainya sebesar $85,37 \%$ dan bulan april sebesar 87,52\% Kondisi ini mengalami kenaikan secara bertahap dari bulan februari sampai dengan maret 2017 dan mempunyai rata-rata sebesar $85,22 \%$.

Berdasarkan perhitungan yang telah dilakukan didapat nilai $O E E$ pada mesin graewe fangli FSSZ 65/132 B pada bulan februari sampai april 2017, bahwa 3 bulan periode hampir setiap bulan total efektivitas penggunaan mesin selalu berada dibawah standar yang ditetapkan oleh JIPM dalam kegiatan produksi karena mempunyai nilai dibawah 0,85 atau 85 $\%$.

Nilai total efektivitas mesin $(O E E)$ sangat dipengaruhi oleh nilai avaibilitas $(A)$, rata-rata kinerja $(P E)$ dan rate of quality yang didapat. Dan didapatkan nilai $O E E$ pada bulan februari sampai april 2016 sebesar 46,95\%. Bila dibandingkan dengan standar JIPM yaitu sebesar > $85 \%$, maka nilai $O E E$ yang didapat masih jauh dari standar.

\section{Diagram pareto perhitungan $\mathrm{OEE}$ six big losses}

Pada diagram pareto ini dapat dilihat urutan penyebab rendahnya nilai $O E E$ mulai dari yang paling besar sampai yang kecil. Pada tabel 4.24 diketahui bahwa faktor six big losses yang paling besar berpengaruh terhadap rendahnya nilai $O E E$ adalah idling and minor stopagges, yang mengakibatkan rendahnya efektivitas penggunaan mesin graewe fangli FSSZ 65/132 B. Dan idling and minor stopagges juga merupakan komponen yang berpengaruh terhadap nilai performance efficiency $(P E)$. Sehingga nilai performance efficiency $(P E)$ rendah dan berdampak pada rendahnya nilai OEE dan kinerja mesin graewe fangli FSSZ 65/132 B menjadi kurang baik.

Tabel 7

Persentase faktor six big losses mesin graewe fangli FSSZ 65/321 B Bulan februari sampai april 2017

\begin{tabular}{|c|c|c|c|c|}
\hline No & Six big loses & $\begin{array}{c}\text { Total time } \\
\text { losses (menit) }\end{array}$ & Presentase & $\begin{array}{c}\text { Persentase } \\
\text { kumulatif }\end{array}$ \\
\hline 1 & $\begin{array}{c}\text { idling and minor } \\
\text { stopagges }\end{array}$ & 33900 & $47,69 \%$ & $47,69 \%$ \\
\hline 2 & reduced speed loss & 24148 & $33,97 \%$ & $81,66 \%$ \\
\hline 3 & yield/scrap loss & 10579 & $14,88 \%$ & $96,54 \%$ \\
\hline 4 & breakdown losses & 1440 & $2,03 \%$ & $98,57 \%$ \\
\hline 5 & setup losses & 1020 & $1,43 \%$ & $100,00 \%$ \\
\hline 6 & rework loss & 0 & $0 \%$ & $100,00 \%$ \\
\hline & Total & 71087 & $100 \%$ & \\
\hline
\end{tabular}

Sumber : data yang sudah diolah

Selanjutnya akan dicari akar penyebab tingginya idling and minor stopagges. Karena berdasarkan diagram pareto jarak antara variabel tertinggi dengan urutan berikutnya sangat signifikan, maka pencarian akar permasalahan hanya difokuskan pada penyebab satu variabel saja yang paling berpengaruh. Hal ini dilakukan supaya lebih fokus dalam mencari akar permasalahan dan menghasilkan usulan perbaikan yang cepat dan tepat.

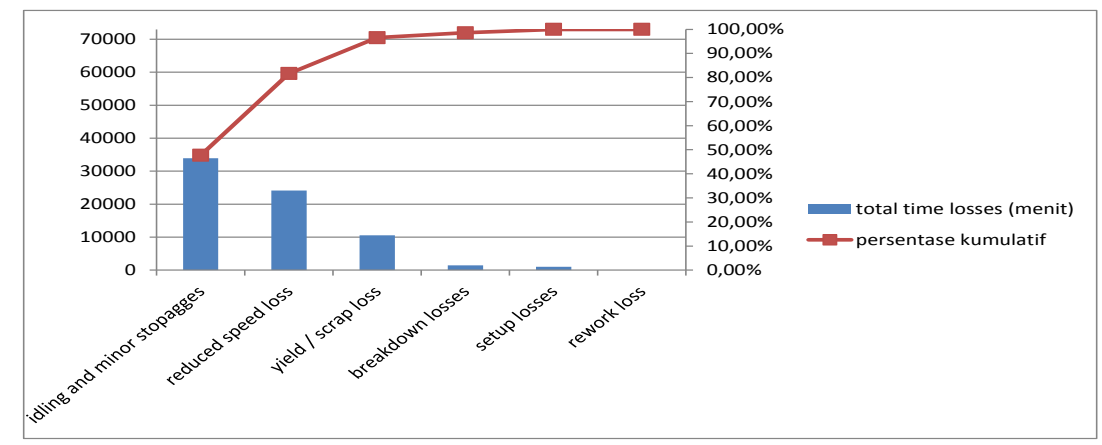

Gambar 1 Diagram pareto six big losses mesin graewe fangli 


\section{Analisis diagram sebab akibat}

Analisa terhadap faktor Yang memberikan konstribusi terbesar penyebab rendahnya efektivitas mesin graewe fangli FSSZ 65/132 B dilakukan dengan menggunakan diagram sebab akibat. Dari data six big losses terdapat satu faktor dominan yang memiliki persentase mencapai $>40 \%$ yaitu idling and minor stopagges maka faktor ini yang akan dianalisa lebih lanjut.

Dari data Six Big Losses bahwa faktor idling and minor stopagges merupakan losses yang paling dominan untuk mesin graewe fangli FSSZ 65/132 B yaitu sebesar 47,69\%. Hal ini menunjukan mesin beroperasi tanpa beban dan berhenti sesaat karena mesin tidak stabil kecepatannya.

Mesin beroperasi tanpa beban produksi antara lain disebabkan oleh :

a. Mesin dibiarkan beroperasi tanpa beban dan tidak menghasilkan produk. Kecepatan produksi mesin/peralatan menurun akibat operator tidak mengetahui berapa kecepatan normal mesin/peralatan.

b. Kecepatan produksi mesin/peralatan menurun jika dipaksa bekerja.

Diagram sebab akibat dari faktor-faktor yang mengakibatkan tingginya idling and minor stopagges pada mesin graewe fangli fangli FSSZ 65/132 B dapat dilihat pada gambar 1.

Selanjutnya, analisis diagram sebab akibat untuk faktor idling and minor stopagges adalah sebagai berikut :

a. Mesin/peralatan

Terjadi gangguan secara tiba-tiba yang disebabkan oleh pemutasan arus listrik oleh PLN dan terdapat kotoran yang menumpuk tidak segera dibersihkan. Kecepatan dan kemampuan mesin menurun yang disebabkan komponen mesin yang sudah tua dan mesin terlalu dipaksakan bekerja melebihi kapasitasnya.

b. Manusia/operator

Kurang telitinya oprarator dalam mengatur kondisi mesin selama proses produksi. Menyebabkan kurangnya konsentrasi operator sehingga pengaturan kerja mesin/peralatan juga terganggu karena kurang diperhatikannya kondisi mesin yang beroperasi tanpa menghasilkan produk.

c. Material

Bahan (resin) yang masuk pada mesin graewe fangli FSSZ 65/132 B terkadang tidak memenuhi standart. Bahan baku (resin) telat masuk kemesin graewe fangli FSSZ 65/132 $B$ karena terhenti di mesin mixer.

d. Lingkungan

Kebersihan lingkungan pada mesin yang kurang terjaga, hal ini terlihat pada banyaknya resin dari hasil proses produksi yang menempel dimesin. Suasana kerja yang kurang mendukung, seperti ruangan yang agak pengap karena kurangnya ventilasi udara.

e. Metode

Perawatan mesin kurang baik hal ini disebabkan frekuensi pengecekan kondisi mesin yang masih sangat rendah dan belum optimal dalam mendokumentasikan permasalahan dan kerusakan terutama dalam kerusakan komponen elektronik

\section{Usulan perbaikan berdasarkan fishbone diagram}

Adapun usulan perbaikan yang dapat dilakukan guna menyelesaikan masalah idling and minor stopagges yang cukup tinggi dapat dilakukan dengan cara : 
Tabel 8 Usulan perbaikan dari diagram fishbone

\begin{tabular}{|c|c|c|}
\hline No & Faktor-faktor & Penyelesaian masalah \\
\hline 1 & $\begin{array}{l}\text { Mesin / peralatan } \\
\text { a. Kotoran yang } \\
\text { menumpuk dimesin } \\
\text { b. Spare part mesin yang } \\
\text { sudah habis masa life } \\
\text { timenya }\end{array}$ & $\begin{array}{l}\text { a. Melakukan perawatan secara rutin dengan } \\
\text { membersihkan panel secara terjadwal } \\
\text { b. Melakukan peremajaan atau pergantian spare } \\
\text { part yang sudah habis masa life timenya }\end{array}$ \\
\hline 2 & $\begin{array}{l}\text { Manusia / operator } \\
\text { a. Konsetrasi menurun } \\
\text { b. Tidak ada training } \\
\text { operator }\end{array}$ & $\begin{array}{l}\text { a. Meningkatkan pengawasan dan pemberian } \\
\text { motivasi kepada operator } \\
\text { b. Pelatihan terhadap operator dilakukan secara } \\
\text { berkala dan sosialisasi secara menyeluruh } \\
\text { mengenai SOP kepada seluruh operator }\end{array}$ \\
\hline 3 & $\begin{array}{l}\text { Material } \\
\text { a. Kondisi bahan baku } \\
\text { tidak standart } \\
\text { b. Terlambatnya material } \\
\text { yang diproduksi oleh } \\
\text { mesin mixer } \\
\end{array}$ & $\begin{array}{l}\text { a. Melakukan pemeriksaan atau quality control } \\
\text { pada matrial yang akan masuk kedalam mesin } \\
\text { b. Membuat jadwal yang terjadwal untuk } \\
\text { ketersediaan matrial yang akan masuk kemesin } \\
\text { produksi }\end{array}$ \\
\hline 4 & $\begin{array}{l}\text { Lingkungan } \\
\text { a. Sirkulasi udara kurang } \\
\text { b. Sisa produksi yang tidak } \\
\text { segera dibersihkan }\end{array}$ & $\begin{array}{l}\text { a. Merenovasi ruangan pada lantai produksi } \\
\text { dengan mengutamakan kesehatan karyawan, } \\
\text { contoh penambahkan ventilasi udara } \\
\text { b. Membuat jadwal piket untuk membersihkan } \\
\text { lingkungan mesin secara teratur }\end{array}$ \\
\hline 5 & $\begin{array}{l}\text { Metode } \\
\text { a. Permasalahan dan } \\
\text { kerusakan belum } \\
\text { terdokumentasi }\end{array}$ & $\begin{array}{l}\text { a. Meningkatkan frekuensi pengecekan disetiap } \\
\text { shift kerja dan melakukan pendokumentasian } \\
\text { daftar permasalahann, pergantian spare part dan } \\
\text { kerusakan. }\end{array}$ \\
\hline
\end{tabular}

\section{KESIMPULAN}

Berdasarkan hasil analisis dan uraian hasil penelitian pada kinerja mesin Graewe Fangli FSSZ 65/132 B di PT PRALON, dapat diambil beberapa kesimpulan yaitu :

Berdasarkan hasil perhitungan nilai Overall Equipment Effectiveness (OEE) pada mesin graewe fangli FSSZ 65/132 B , telah dapat dilihat bahwa OEE berkisar antara 44,22 \% sampai $52,68 \%$. Dimana nilai $O E E$ terbesar ada pada bulan maret yaitu sebesar 52,68 \%, karena pada bulan tersebut nilai quality rate tinggi merupakan masa-masa bulan awal mesin beroperasi dengan baik sehingga good produk terjaga dan scrap produk mesin cukup sedikit. Selanjutnya, OEE ratarata sebesar 46,95\%. Kondisi ini menunjukan bahwa kemampuan mesin graewe fangli FSSZ $65 / 132 B$ dalam mencapai target dan dalam pencapaian efektivitas penggunaan mesin/peralatan belum mencapai kondisi ideal sesuai standar JIPM yaitu berada diatas $85 \%$.

Hasil perhitungan terhadap nilai OEE six big losess diketahui bahwa selama 3 bulan februari 2016 sampai dengan april 2016 faktor yang paling besar pengaruhnya terhadap nilai $O E E$ adalah idling and minor stopagges yaitu 47,69 \% dari keseluruhan loss terbesar yang mempengaruhi nilai $O E E$. Dimana nilai idling and minor stopa terbesar terjadi pada bulan maret 2016 karena pada periode tersebut jumah actual non productive time tinggi.

Hasil dari analisis fishbone diagram menunjukan bahwa dari kelima faktor yaitu mesin, manusia, material, metode dan lingkungan mempengaruhi terjadinya reduce speed loss yang tinggi. Jadi beberapa usualan perbaikan yang penulis berikan adalah Melakukan perawatan secara rutin, Meningkatkan pengawasan dan pemberian motivasi kepada operator, Meningkatkan Melakukan pemeriksaan atau quality control pada matrial, Merenovasi ruangan pada lantai produksi dengan mengutamakan kesehatan karyawan, Meningkatkan frekuensi pengecekan disetiap shift kerja dan melakukan pendokumentasian daftar permasalahann, pergantian spare part dan kerusakan. 


\section{SARAN}

Beberapa saran yang diharapkan dapat memberikan masukan dan manfaat berdasarkan hasil penelitian ini adalah Melakukan perhitungan $O E E$ pada setiap mesin disetiap stasiun, Untuk menghilangkan atau meminimalkan faktor six big losess yang terjadi, Perusahaan harus menerapkan Total Productive maintenance (TPM) sebagai salah satu usaha untuk mencapai kinerja perawatan yang optimal dan harus dilakukan dengan sungguh-sungguh dan konsisten. Oleh karena itu perusahaan perlu menanamkan kesadaran kepada seluruh karyawan untuk dapat berperan aktif dalam peningkatan kinerja mesin untuk memperlancar dan memaksimalkan kegiatan-kegiatan oprasional pabrik khususnya pada proses produksi.

\section{DAFTAR PUSTAKA}

Tannady, Hendy. 2015. Pengendalian Kualitas, cetakan pertama. Yogyakarta: Graha Ilmu.

Kurniawan, Fajar. 2013. Manajemen Perawatan Industri, Cetakan pertama. Yogyakarta: Graha Ilmu.

Et al, Duffua. 1999. Planning and Control Maintenance System, Jhon Wiley \& Sons. Terjemahan N. Ansori \& M. Imron Mustajib, 2013, Sistem Perawatan Terpadu (Integrated maintenance System), edisi pertama. yogyakarta: Graha Ilmu.

Fauzi, Nur A. 2014. Analisa total produktifitas maintenance pada mesin machining center pada PT Hitachi Power System Indonesia (HPSI) dengan menggunakan metode Overall Equipment Effectiveness (OEE). Vol. 25 No. 7 709-756.

Hardiadi, ikhsan 2016. ANALISIS KINERJA MESIN HGF C32MT DENGAN METODE OVERALL EQUIPMENT EFFECTIVENESS (OEE)DAN USULAN PERBAIKANYA MENGGUNAKAN FISHBONE DIAGRAM PADA PABRIK GULA NGADIREDJO. Surabaya

Mas'ud sahib, M. Khairul ; Irman, Ade. 2014. Analisis dan pengukuran nilai mesin spinning poy menggunakan metode Overall Equipment Effectiveness (OEE). Vol. 10 No. 2: 108-199. 